University of Nebraska - Lincoln

DigitalCommons@University of Nebraska - Lincoln

Faculty Publications: Department of Entomology

Entomology, Department of

2-1-1998

\title{
Identification of Mealybug- (Homoptera: Pseudococcidae) Resistant Turf-Type Buffalograss Germplasm
}

Jennifer Johnson-Cicalese

Rutgers University, jenjc@aesop.rutgers.edu

Frederick P. Baxendale

University of Nebraska-Lincoln, fbaxendale1@unl.edu

Terrance P. Riordan

University of Nebraska-Lincoln, triordan1@unl.edu

Tiffany Heng-Moss

University of Nebraska-Lincoln, thengmoss2@unl.edu

Follow this and additional works at: https://digitalcommons.unl.edu/entomologyfacpub

Part of the Entomology Commons

Johnson-Cicalese, Jennifer; Baxendale, Frederick P.; Riordan, Terrance P.; and Heng-Moss, Tiffany, "Identification of Mealybug- (Homoptera: Pseudococcidae) Resistant Turf-Type Buffalograss Germplasm" (1998). Faculty Publications: Department of Entomology. 140.

https://digitalcommons.unl.edu/entomologyfacpub/140

This Article is brought to you for free and open access by the Entomology, Department of at DigitalCommons@University of Nebraska - Lincoln. It has been accepted for inclusion in Faculty Publications: Department of Entomology by an authorized administrator of DigitalCommons@University of Nebraska - Lincoln. 


\title{
Identification of Mealybug- (Homoptera: Pseudococcidae) Resistant Turf-Type Buffalograss Germplasm
}

\author{
JENNIFER JOHNSON-CICALESE, ${ }^{1}$ FREDERICK BAXENDALE, ${ }^{2}$ TERRANCE RIORDAN, ${ }^{3}$ \\ AND TIFFANY HENG-MOSS ${ }^{2}$
}

\begin{abstract}
J. Econ. Entomol. 91 (1): 340-346 (1998)
ABSTRACT Two species of mealybugs, Tridiscus sporoboli (Cockerell) and Trionymus sp., have emerged as potentially serious pests of turf-type buffalograss, Buchloë dactyloides (Nuttall) Engelmann. Sixty-two buffalograss selections were screened for resistance to these mealybugs in 4 greenhouse trials. Using a $1-6$ rating scale ( $1=$ no signs of mealybugs, $6=>75 \%$ of tillers infested), 'Prairie' and '609' showed high levels of resistance to mealybugs, whereas several experimental selections, including 90-157, 84-512 and 84-412, exhibited moderate resistance. Most selections were moderately susceptible, and 85-97 was highly susceptible with almost every tiller infested and plants near death. In field tests, mealybug infestations were highly variable, both within and among plots. However, in most cases, selections evaluated in the field showed similar responses as in greenhouse trials. Pubescence was positively correlated with buffalograss susceptibility to mealybugs. A glabrous leaf surface is suggested as a possible mechanism of resistance.
\end{abstract}

KEY WORDS Tridiscus sporoboli, Trionymus sp., mealybugs, plant resistance, buffalograss, turfgrass

ENVIRONMENTAL CONCERNS AND water shortages have prompted turfgrass managers to search for new grass species with lower maintenance requirements. Buffalograss, Buchloë dactyloides (Nuttall) Engelmann, is a warm-season grass native to North America that has potential to fill this niche because of its excellent drought tolerance, low growth habit, and minimal fertility requirements. This forage and conservation grass (Wenger 1943, Beetle 1950) is now receiving attention as an alternative turfgrass (Huff and Wu 1987, Engelke and Lehman 1990, Riordan et al. 1993). At the University of Nebraska, Lincoln, NE, studies are underway to develop buffalograss cultivars with improved turfgrass characteristics, develop management strategies for turf-type buffalograsses, and identify potential disease and insect pests (Riordan et al. 1993).

Two recently identified and potentially serious pests of buffalograss are the mealybugs Tridiscus sporoboli (Cockerell) and Trionymus sp. These insects were first detected damaging buffalograss evaluation plots near Mead, NE, in 1988 (Baxendale et al. 1994). Mealybugs have since been collected from buffalograss stands throughout Nebraska (Baxendale et al. 1994) and in Texas and Arizona (J.J.-C., unpublished data), indicating a widespread distribution. Because the 2 mealybug species are nearly

\footnotetext{
${ }^{1}$ Plant Science Department, Foran Hall, Cook College, Rutgers University, New Brunswick, NJ 08903-0231.

${ }^{2}$ Entomology Department, 209 Plant Industry, University of Nebraska, Lincoln, NE 68583-0816.

${ }^{3}$ Horticulture Department, 377 Plant Science, University of Nebraska, Lincoln, NE 68583-0724.
}

identical in appearance, their relative abundance is not known.

Little is known about the biology of these mealybugs (Baxendale et al. 1994). Adult females are dark pink, relatively immobile, and usually found within the leaf sheath where their eggs are deposited. First instars (crawlers) disperse to new feeding sites. Generation times may be as short as $30 \mathrm{~d}$ (McKenzie 1967). Mealybugs damage plants by removing sap with their piercing-sucking mouthparts. Infested turf shows symptoms similar to drought stress and the foliage takes on a dull reddish-grey discoloration, followed by browning and thinning. Detection of the insect is difficult because of its small size $(0.2-3.0 \mathrm{~mm})$ and hidden location. However, during severe infestations, the masses of white cottony wax produced by the female are usually visible. Several parasitoid wasps (family Encyrtidae) have been identified and found to play a role in regulating populations of these mealybugs (Heng-Moss 1997).

Developing grasses with resistance to insects offers an environmentally sound and sustainable approach for managing pests. Insect resistance has been documented in many forage and turfgrass species (Schuster and Dean 1973, Reinert 1982, Campbell et al. 1984, Meyer and Funk 1989, JohnsonCicalese et al. 1989, Quisenberry 1990), suggesting the potential for developing insect-resistant buffalograss cultivars. The objectives of this study were to develop screening methods and to evaluate buffalograss germplasm for resistance to the mealybugs Tridiscus sporoboli and Trionymus sp. 


\section{Materials and Methods}

Field Evaluations. In autumn 1988, a severe mealybug infestation was detected on several buffalograss field trials located at the J. S. Anderson Turfgrass Research Facility, University of Nebraska Agricultural Research and Development Center (ARDC) near Mead, NE (Baxendale et al. 1994). This infestation provided an opportunity to evaluate buffalograss genotypes for resistance to mealybugs.

Twenty-four genotypes were evaluated, 8 in a trial that had been established in 1986, and 16 in a trial established in 1987. Both trials contained 50 experimental genotypes in plots that were 2.4 by $2.4 \mathrm{~m}$ and replicated 4 times in a randomized complete block design. Plot maintenance included biweekly mowing at $6 \mathrm{~cm}$, fertilization with $0.5-0.7 \mathrm{~kg}$ $\mathrm{N} / 100 \mathrm{~m}^{2} / \mathrm{yr}$, pre- and postemergence herbicides as needed (Gaussoin et al. 1994), and irrigation during the establishment year. To obtain mealybug counts, the vegetation from $460 \mathrm{~cm}^{2}$ was removed from each plot and placed in Berlese funnels (Southwood 1979) for $72 \mathrm{~h}$ to extract insects. Samples were taken on 30 May 1989, and biweekly thereafter until 29 August 1989.

In August 1994, signs of mealybug infestation were evident in a 1990 buffalograss planting. Five of the 98 entries in this planting were standards ('Texoka', Prairie, '378', '315', and 84-45-3) and the remaining 93 entries were vegetatively propagated experimental selections. The trial was replicated 3 times in a randomized complete block design and plot size was 1.5 by $1.5 \mathrm{~m}$. Maintenance was the same as in the 1986 and 1987 trials described above. Mealybug counts for 33 entries were obtained by harvesting vegetation $\left(230 \mathrm{~cm}^{2}\right)$ and extracting the insects in Berlese funnels. Samples were taken in late $\mathrm{Au}-$ gust 1994 from all 3 replications. On 5 September 1994, all plots were rated for mealybug damage using a 1-9 scale, where $1=$ severe discoloration or thinning, and $9=$ no reddish-grey discoloration, dead tissue or thinned turf.

Because of previous observations that leaf pubescence might be involved in mealybug susceptibility, the trial was also rated for pubescence in July 1995. A $1-6$ rating scale was used, where $1=$ no pubescence and $6=$ dense trichomes. This pubescence rating scale was developed during greenhouse trials by examining several hundred buffalograss plants and grouping them into categories. Plants with the densest pubescence were designated as 6 's and had $\approx 30 \%$ of their leaf surface covered with trichomes. Plants with less pubescence were scaled accordingly, for example, $4=\approx 18 \%$ of leaf surface covered with trichomes. The accuracy of this rating scale was evaluated in another study and found to be highly correlated with actual trichome counts (JohnsonCicalese 1995).

Greenhouse Screening. Trial 1. Plugs from 38 buffalograss selections were extracted from plots in December 1991. The selections were of diverse origins and were among the top performers in turf- grass quality evaluations. Six plugs $(10 \mathrm{~cm}$ diameter by $6 \mathrm{~cm}$ deep) of each selection were planted in $15-\mathrm{cm}$ pots in a potting mix containing $0.66 \mathrm{sand} /$ 0.33 soil (Sharpsburg silty clay loam) $/ 1$ peat $/ 1$ perlite. Plants were placed under 400-W high-intensity discharge lamps with a photoperiod of 12:12 (L:D) $\mathrm{h}$, and temperatures were maintained at $24 \pm 3^{\circ} \mathrm{C}$. Approximately every $4 \mathrm{wk}$, plants were clipped to 10 $\mathrm{cm}$ and fertilized with a soluble (20.0:4.4:16.6, $\mathrm{N}: \mathrm{P}: \mathrm{K})$ fertilizer to maintain healthy growth.

In May 1992, mealybugs that had inadvertently been brought into the greenhouse from the field were found on nearly half of the buffalograss plants. Because of this infestation, a study was started to screen the selections for resistance using a completely randomized design with 6 replications. Grass clippings from infested plants were spread evenly over the pots as inoculum to encourage a uniform mealybug infestation. Mealybug infestation ratings were made 4 and $7 \mathrm{wk}$ after inoculation. Because the mealybug itself was rarely visible, the ratings were based primarily on signs of mealybug presence, such as the white cottony masses of wax deposited by the female or the reddish discoloration of an infested tiller. A $1-6$ rating scale was developed where $1=$ no mealybugs or cottony masses; 2 = a single sign of mealybugs; $3=\approx 10-25 \%$ of tillers infested; $4=$ $26-50 \%$ of tillers infested; $5=51-75 \%$ of tillers infested; and $6=>75 \%$ of tillers infested and plant close to death. In late June, $30 \mathrm{~d}$ after cutting, regrowth was evaluated using a 1-9 rating scale where $1=$ no growth, and $9=$ best growth. (The 1-9 rating scale, where $9=$ best, is the standardized turfgrass evaluation scale [Skogley and Sawyer, 1992]. The 6-increment scale, however, where $1=$ none and $6=$ most, was more useful for mealybug infestation and pubescence ratings because differences were harder to separate [Smith et al. 1994].)

Trials 2-4. Additional trials were conducted to confirm results obtained in trial 1 and to evaluate additional buffalograss genotypes. Plugs were removed from field plots, planted, and maintained as previously described. Pots were arranged on a greenhouse bench in a randomized complete block design with 4 replications, except trial 4 which had 6 replications. Based on results from trial 1, the cultivar ' 609 ' and experimental selection 85-97 were included in each trial as the resistant and susceptible controls, respectively. All plants were evaluated for mealybug infestation using the 1-6 rating scale, where $1=$ no mealybugs. Plants were also rated for leaf pubescence using a 1-6 scale, where $1=$ no pubescence.

In trial 2,25 of the selections from trial 1 were reevaluated. Plugs were removed from plots in July 1992, and inoculated with mealybug-infested grass clippings in August. Plants were rated in September, October, November, and January for mealybug infestation and turf quality (1-9 scale, where $9=$ best density, color and overall appearance). Upon com- 
pletion of the trial, $3 \mathrm{~g}$ of vegetation from each pot were clipped at soil level and placed in Berlese funnels for mealybug extraction.

In trial 3, plugs from 30 different selections were removed from the field in April 1993. Plants were inoculated with infested clippings in May, and because of a low level of infestation, reinoculated in June and July. The trial was evaluated for mealybug infestation in June, July, and again in January. Mealybug numbers were monitored from September through October 1993 by placing a sticky stake in the soil of each pot (Heng et al. 1994). The sticky stakes were $12.5-\mathrm{cm}$ plastic pot labels with a $4-\mathrm{cm}$ piece of double-coated adhesive tape placed on each side. Stakes were changed weekly and captured insects were counted.

Five selections that were of high interest to the buffalograss breeding program were reevaluated in trial 4, along with the susceptible control 85-97. Plugs were brought in from the field in July 1994. Because parasitoid wasps probably played a role in reduced mealybug numbers in trial 3 , efforts were made to minimize wasp infestation. Plants were clipped to soil level and the vegetation removed to eliminate above-ground arthropods. A tubular cage of clear acetate ( $12 \mathrm{~cm}$ diameter by $30 \mathrm{~cm}$ high) was placed over each pot and the top of the tube was covered with organdy fabric. Plants were allowed to regrow for 3 wk. Immature mealybugs were removed individually from wasp-free plants and placed on the plants. The trial was inoculated twice in early August, with 20 mealybugs per inoculation. Mealybug ratings were taken biweekly, late September through November. Sticky stakes were used to monitor immature mealybugs and parasitoid wasps, and were changed and counted biweekly. In early November, half of the vegetation from each pot was removed and placed in a Berlese funnel to obtain mealybug counts. The other half of each plant was harvested and mealybugs extracted $2 \mathrm{wk}$ later.

Field Cage Trial. PVC-pipe enclosures $(15 \mathrm{~cm}$ diameter by $20 \mathrm{~cm}$ high) were placed in replicated field plots of 12 buffalograss selections. A randomized complete block design was used with 2 replications and 3 subsamples (cages) per replication ( 6 cages per selection). The cages were infested with mealybugs in July 1992 using a small sample of clippings from greenhouse screening trial 1 . The grass within the cages was rated weekly for turf quality ( $1-9$ scale, where $1=$ worst quality and $9=$ best $)$. In late August, plants within the cages were harvested and insects were extracted to obtain mealybug counts.

Statistical Analysis. Analysis of variance was calculated for each rating or count, and when a significant $F$ ratio occurred $(P<0.05)$, means were separated using the least significant difference (LSD) test (SAS Institute 1988). Correlations between variables were analyzed using the Pearson correlation tests (SAS Institute 1988).
Table 1. Numbers of mealybugs found on buffalograss selections during a natural field infestation in 1989 , near Mead, NE

\begin{tabular}{ll}
\hline $\begin{array}{c}\text { Cultivar or } \\
\text { selection }\end{array}$ & $\begin{array}{c}\text { Mealybug } \\
\text { no. } \pm \text { SEM }^{a}\end{array}$ \\
\hline $85-4569$ & $106.9 \pm 110.9$ \\
Texoka & $108.2 \pm 37.9$ \\
$84-W S$ & $126.4 \pm 82.7$ \\
$378^{\prime}$ & $184.3 \pm 65.5$ \\
$84-22-2$ & $223.9 \pm 44.6$ \\
$84-923$ & $225.7 \pm 181.7$ \\
$85-97$ & $381.8 \pm 106.4$ \\
$84-924$ & $392.9 \pm 255.9$ \\
$85-158-2$ & $450.9 \pm 307.1$ \\
LSD (0.05) & 209.3 \\
Mean & 248.2 \\
\hline
\end{tabular}

Field trial established in 1987

a Mealybugs per $460 \mathrm{~cm}^{2}$ of vegetation, extracted in Berlese funnels, average of 8 sampling dates.

\section{Results and Discussion}

Field Evaluations. Large numbers of mealybugs were collected from the 1987 planting, with a mean of 800.2 mealybugs per $460 \mathrm{~cm}^{2}$ of buffalograss collected on 6 June 1989. However, numbers declined sharply and by late August the mean mealybug count was only 3.1 per $460 \mathrm{~cm}^{2}$. There was considerable variation in mealybug numbers within selections. Among the 16 selections, significant differences were only detected on 21 June $1989(F=2.44$; $\mathrm{df}=15,45 ; P<0.0109)$ and for the average mealybug counts $(F=1.98$; df $=15,45 ; P<0.0390)$ (Table 1). Selections 85-97, 84-924, and 85-158-2 appeared to be highly susceptible, whereas $85-4569$ and Texoka had significantly lower mealybug counts.

In the 1986 planting, mealybug numbers were lower (overall mean of 5.5 mealybugs per $460 \mathrm{~cm}^{2}$ compared with 248.2 in the 1987 planting). Significant differences in mealybug numbers were detected for the average mealybug counts $(F=3.39$; $\mathrm{df}=7,21 ; P<0.0139$, data not shown), with ' 609 ' having the fewest mealybugs (2.8) and ' 315 ' having the most (9.8). The 1986 planting likely had a greater mealybug infestation during the previous year, based on the severe damage observed (T.R., unpublished data), and the population had declined by the time sampling started in 1989. This decline in mealybug population may have been related to the large numbers of parasitoid wasps and predatory mites that were present in the samples (F.B., unpublished data).

In the 1994 field evaluations, mealybug numbers were highly variable, but significant differences were detected among the 33 selections evaluated $(F=1.91 ; \mathrm{df}=33,66 ; P<0.0129)($ Table 2$)$. Prairie had significantly fewer mealybugs than ' 315 ', 16.0 compared with 241.4. Selections also differed in the degree of mealybug damage $(F=6.29 ; d f=97,194$; $P<0.0001$ ) (Table 2). However, these damage ratings $(9-1,9=$ no damage) were not negatively correlated with mealybug counts $\left(r^{2}=0.35, P=\right.$ 0.0489 ). This lack of correlation may have been 
Table 2. Sugceptibility of buffalograss selections to mealybugs during a natural field infestation near Mead, NE, 1994

\begin{tabular}{lccc}
\hline $\begin{array}{c}\text { Cultivar or } \\
\text { selection }\end{array}$ & $\begin{array}{c}\text { Mealybug } \\
\text { no. } \pm \text { SEM }^{a}\end{array}$ & $\begin{array}{c}\text { Damage } \\
\text { rating }\end{array}$ & $\begin{array}{c}\text { Pubescence } \\
\text { rating }^{c}\end{array}$ \\
\hline $90-13$ & $6.6 \pm 6.1$ & 6.0 & 4.7 \\
Prairie & $16.0 \pm 27.7$ & 7.0 & 2.0 \\
$90-27$ & $50.0 \pm 29.1$ & 6.7 & 2.0 \\
$90-69$ & $75.4 \pm 14.7$ & 5.3 & 2.7 \\
378 ' & $87.4 \pm 64.0$ & 5.0 & 5.3 \\
$90-20$ & $96.0 \pm 60.9$ & 7.0 & 1.0 \\
$84-45-3$ & $110.0 \pm 89.9$ & 5.0 & 3.7 \\
Texoka & $138.0 \pm 150.0$ & 6.0 & 4.7 \\
'315' & $241.4 \pm 233.3$ & 5.7 & 3.3 \\
$90-30$ & $252.6 \pm 314.1$ & 7.0 & 5.0 \\
$90-12$ & $510.6 \pm 331.1$ & 7.7 & 4.7 \\
LSD (0.05) & 183.2 & 1.1 & 1.0 \\
Mean & 108.6 & 6.0 & 4.5 \\
\hline
\end{tabular}

${ }^{a}$ Mealybugs per $460 \mathrm{~cm}^{2}$ of vegetation, extracted September in Berlese funnels.

${ }^{b}$ Mealybug damage rating scale $9-1 ; 9$, no damage or discoloration from mealybugs; 1 , severe discoloration or damage; 5 September.

c Pubescence rating scale $1-6 ; 1$, no pubescence; 6 , very dense trichomes.

caused partially by mealybug-tolerant selections, which would have high mealybug counts but exhibit little damage, such as selection 90-12. It had the highest number of mealybugs and the least damage (Table 2). However, it was difficult to distinguish mealybug damage from other stress factors, and mealybug distribution can be patchy over both space and time.

Pubescence ratings of the 98 selections in this trial showed a negative correlation with damage ratings $\left(r^{2}=-0.44, P=0.0001\right)$ (i.e., selections with little to no leaf pubescence had less mealybug damage [Table 2]). For example, Prairie, 90-20, and 90-27 were glabrous, and had little damage and relatively low mealybug counts.

Greenhouse Screening. Trial 1. Significant differences among mealybug infestation ratings were detected $4 \mathrm{wk}$ after inoculation $(F=5.18 ; \mathrm{df}=37,186$; $P<0.0001$ ), with '609', Prairie, and 84-412 showing resistance, and 85-97 showing extreme susceptibility (Table 3). Mealybug ratings showed a significant negative correlation with regrowth ratings $\left(r^{2}=\right.$ $-0.87, P=0.0001$ ), indicating that mealybugs were adversely affecting plant health. When plants were rated 3 weeks later, mealybug pressure was so severe that most plants, including resistant types, were infested (mean mealybug rating $=5.7$, data not shown). However, '609' was still highly resistant, with a significantly lower mealybug rating of 2.2 $(F=49.83 ; \mathrm{df}=37,190 ; P<0.0001)$.

Trial 2. Significant differences in mealybug infestation ratings were observed on each of the 4 evaluation dates and for the average of these ratings (average: $F=18.05$; $\mathrm{df}=26,78 ; P<0.0001$ ) (Table 3 ). The relative ranking of the 25 selections was similar to trial 1 . The mealybug counts obtained were relatively low (mean $=18.7$ mealybugs per $3 \mathrm{~g}$ foliage), probably because the mealybug population had begun to decline. However, there were significant differences in mealybug numbers $(F=4.62$; $\mathrm{df}=26,77 ; P<0.0001$ ) and the counts correlated with average mealybug infestation ratings $\left(r^{2}=\right.$ $0.46, P=0.0156$ ) (Table 3).

Significant negative correlations were found between turf quality and mealybug infestation ratings

Tahle 3. Susceptibility of huffalograss selections to mealybugs under greenhouse conditions

\begin{tabular}{|c|c|c|c|c|}
\hline \multirow{2}{*}{$\begin{array}{l}\text { Cultivar or } \\
\text { selection }\end{array}$} & \multirow{2}{*}{$\frac{\text { Trial } 1}{\text { Mealybug }_{\text {rating }^{a}}}$} & \multicolumn{2}{|c|}{ Trial 2} & \multirow{2}{*}{$\begin{array}{l}\text { Pubescence } \\
\text { rating }^{d}\end{array}$} \\
\hline & & $\begin{array}{l}\text { Mealybug } \\
\text { rating }\end{array}$ & $\begin{array}{c}\text { Mealybug } \\
\text { no. }\end{array}$ & \\
\hline ‘609’ & 1.7 & 1.2 & 1.4 & 1.2 \\
\hline Prairie & 2.8 & 2.0 & 5.3 & 2.3 \\
\hline $84-512$ & 3.3 & 2.4 & 12.3 & 2.5 \\
\hline $84-412$ & 3.0 & 3.1 & 17.3 & 1.0 \\
\hline $84-714$ & 3.3 & 3.6 & 18.8 & 2.8 \\
\hline $85-217$ & 3.5 & 3.6 & 8.0 & 5.0 \\
\hline ' $315 ’$ & 3.5 & 4.2 & 4.3 & 3.3 \\
\hline$' 378$ ' & 3.7 & 4.0 & 16.3 & 4.5 \\
\hline $84-931$ & 4.6 & 3.3 & 11.0 & 4.8 \\
\hline $84-926$ & 4.5 & 3.4 & 15.0 & 4.0 \\
\hline $84-925$ & 4.5 & 3.4 & 18.3 & 4.0 \\
\hline Texoka & 4.2 & 3.7 & 21.3 & 5.3 \\
\hline 84-WS & 3.8 & 4.1 & 24.0 & 4.5 \\
\hline $84-923$ & 4.2 & 3.8 & 28.8 & 3.5 \\
\hline $84-930$ & 5.0 & 3.3 & 12.8 & 4.0 \\
\hline $84-924$ & 4.7 & 3.5 & 30.0 & 3.8 \\
\hline $84-928$ & 5.2 & 3.9 & 12.8 & 4.0 \\
\hline $84-22-2$ & 4.8 & 4.2 & 17.0 & 4.8 \\
\hline $85-97$ & 5.4 & 4.6 & 32.0 & 5.3 \\
\hline Mean & 4.2 & 3.5 & 18.7 & 3.8 \\
\hline LSD & 0.8 & 0.6 & 19.6 & 0.6 \\
\hline
\end{tabular}

Mealybug infestation rating 4 wk after inoculation, 1-6 scale; 1 , no mealybugs; $6,>75 \%$ of tillers infested.

${ }^{b}$ Average of 4 mealybug infestation ratings.

"Mealybugs per $3 \mathrm{~g}$ plant foliage, extracted in Berlese funnels.

${ }^{d}$ Pubescence rating $1-6$ scale; 1 , no pubescence; 6 , very dense trichomes. 
Table 4. Susceptibility of buffalograss selections to mealybugs under greenhouse conditions

\begin{tabular}{|c|c|c|c|c|}
\hline \multirow{2}{*}{$\begin{array}{l}\text { Cultivar } \\
\text { or selection }\end{array}$} & \multicolumn{2}{|c|}{ Mealybug rating ${ }^{a}$} & \multirow{2}{*}{$\frac{\text { Mealybug no. }}{{ }^{b}}$} & \multirow{2}{*}{$\begin{array}{l}\text { Pubescence } \\
\text { rating }^{c}\end{array}$} \\
\hline & Trial 3 & Trial 4 & & \\
\hline${ }^{\prime} 609 ’$ & 1.3 & & & 1.0 \\
\hline Prairie & 1.0 & & & 1.0 \\
\hline Buffalawn & 1.3 & & & 1.0 \\
\hline $90-69$ & 1.3 & & & 3.8 \\
\hline $90-157$ & 1.3 & 1.3 & 0.9 & 4.5 \\
\hline $90-163$ & 1.3 & 3.1 & 9.6 & 4.5 \\
\hline $90-164$ & 1.5 & 2.1 & 2.4 & 5.8 \\
\hline $90-167$ & 1.5 & 2.6 & 4.8 & 5.0 \\
\hline $90-160$ & 1.8 & 3.6 & 11.7 & 4.0 \\
\hline AZ-143 & 1.3 & & & 5.0 \\
\hline ‘315’ & 1.3 & & & 3.5 \\
\hline$‘ 378^{\prime}$ & 1.8 & & & 4.5 \\
\hline $84-45-3$ & 1.8 & & & 4.0 \\
\hline Sharps improved & 1.3 & & & 4.8 \\
\hline Topgun & 1.5 & & & 4.3 \\
\hline Tatanka & 2.0 & & & 5.0 \\
\hline Bison & 1.8 & & & 5.0 \\
\hline Plains & 2.5 & & & 4.8 \\
\hline $85-97$ & 3.0 & 4.2 & 27.3 & 5.8 \\
\hline Mean & 1.5 & 2.8 & 9.3 & 3.7 \\
\hline LSD & 0.8 & 1.0 & NS & 0.6 \\
\hline
\end{tabular}

${ }^{a}$ Mealybug infestation rating 1-6 scale; 1, no mealybugs; $6,>75 \%$ of tillers infested. Trial 3 ratings made in July 1993 , and Trial 4 ratings are an average of 4 ratings.

${ }^{b}$ Mealybugs per $3 \mathrm{~g}$ plant foliage, average of 2 counts, extracted November 1994 in Berlese funnels.

${ }^{c}$ Pubescence rating 1-6 scale; 1 , no pubescence, 6 , very dense trichomes.

(e.g., for 6 January ratings, $r^{2}=-0.84, P=0.0001$ ), indicating that mealybug feeding was affecting turf quality. In addition, mean turf quality dropped from a rating of 5.3 at the beginning of the study to 4.4 at its conclusion. Pubescence and mealybug infestation ratings were highly correlated $\left(r^{2}=0.79, P=\right.$ 0.0001 ). This correlation suggested that pubescence may play a role in buffalograss susceptibility to mealybugs. Glabrous selections ' 609 ' and $84-412$, and nearly glabrous Prairie and 84-512 showed resistance, whereas most of the highly pubescent selections were susceptible (Table 3 ).

Trial 3. Significant differences in mealybug infestation ratings were found among the 30 selections evaluated $(F=1.96 ; \mathrm{df}=29,87 ; P<0.0089)$ (Table 4). However, this trial never developed a heavy mealybug infestation because of a high parasitoid wasp population. Only 53 mealybugs were caught on the sticky stakes, whereas 38 parasitoid wasps were captured during the same 6-wk collection period. Two months after initiation of the study, the mean mealybug rating was only 1.5 (as compared with 3.5 in trial 2) and the infestation did not develop further.

Pubescence evaluations correlated with mealybug infestation ratings $\left(r^{2}=0.52, P=0.0032\right)$. It was interesting to note that the 5 buffalograss selections with a diploid chromosome number ('Buffalawn' and 4 others not reported herein), and the 2 tetraploid selections ('609' and Prairie) in this trial, were glabrous and had low mealybug infestation ratings. Most of the other buffalograsses evaluated were hexaploids. The possible relationship among ploidy level, pubescence, and mealybug susceptibility warrants investigation.
Trial 4. The modified inoculation technique used for this trial resulted in a relatively wasp-free mealybug infestation. Significant differences in mealybug-infestation ratings were detected among the 6 selections evaluated $(F=8.77 ; \mathrm{df}=5,23 ; P<$ 0.0001 ) (Table 4). As observed in trial 3 , selection 90-157 had resistance to mealybugs. Unfortunately, sticky stake counts were very low and did not reflect the level of mealybug infestation well in this trial. No significant differences were found in stake counts (average: $F=1.53 ; \mathrm{df}=5,23 ; P<$ 0.2195 ), nor for counts obtained through Berlese extraction (average: $F=2.07 ; \mathrm{df}=5,21 ; P<$ 0.1095 ). However, Berlese counts were positively correlated with mealybug ratings $\left(r^{2}=0.90, P=\right.$ 0.0158 ) (Table 4). All selections evaluated in this trial had pubescent leaves, with ratings ranging from 4.0 to 5.8 . Thus, no correlation between pubescence and susceptibility was found. This suggested that $90-157$ may have mealybug resistance that is unrelated to glabrousness.

Both inoculation techniques used in these greenhouse trials provided uniform mealybug infestations. However, scattering infested tillers (trials 1-3) permitted screening large numbers of selections, while inoculating with individual mealybugs (trial 4) was time consuming. In either case, precautions should be taken to minimize parasitoid wasp infestations. Sticky stakes were useful for monitoring the wasps.

Field Cage Trial. Mealybug counts obtained from field cages were generally consistent with greenhouse screening trials. For example, ' 609 ' had the fewest mealybugs with a mean of $39.8 \pm 4.7$, Prairie had $122.5 \pm 33.4$, Texoka had $310.2 \pm 138.7,85-97$ 
had $439.0 \pm 160.9$, and ' 378 ' had the highest mean number at $765.0 \pm 401.1$ (overall mean $=380.1$ ). However, these mealybug counts were not significantly different from each other $(F=1.20$; df $=11$, $11 ; P<0.3828$ ) because of the high variability in mealybug numbers among cages (range, 16 to 2,728 mealybugs per cage). The cages adversely affected the turf, so the quality ratings did not reflect the level of mealybug damage. The use of field cages may provide useful field data if more replications are used, or the inoculum is more uniform (i.e., inoculating with an exact number of mealybugs instead of using infested clippings).

Our results indicate the potential to screen for resistant germplasm and improve buffalograss resistance to mealybugs in commercial cultivars. A wide range in susceptibility was found among the selections we screened; '609' and Prairie consistently showed excellent resistance to mealybugs, and several experimental selections, including 90-157, 84512 and $84-412$, exhibited moderate resistance. Most selections were moderately susceptible, although 85-97 was highly susceptible. The highly resistant ' 609 ' was the 1st cultivar released from the Nebraska buffalograss breeding program (Riordan et al. 1992) and was being evaluated while the yet undiscovered mealybug population was reaching its peak at the research station near Mead, NE. The mealybug resistance in ' 609 ' could have contributed to its consistently high-quality ratings compared with other buffalograss lines.

The methods developed herein to screen buffalograss for mealybug resistance were successful. Spreading infested tillers was a rapid, effective inoculation technique, although precautions are needed to minimize parasitoid wasp populations. Mealybug infestation ratings were time efficient and good indicators of the level of buffalograss susceptibility. Our mealybug counts, however, were often highly variable, and a more accurate method for estimating mealybug populations is needed. Additional studies are focused on glabrousness as a possible mechanism of resistance, and the inheritance of mealybug resistance in buffalograss (JohnsonCicalese 1995). These research efforts will be used in the development of buffalograss cultivars that provide quality, low-input turfgrass stands.

\section{Acknowledgments}

We gratefully acknowledge Z B Mayo, R. Gaussoin, G. Horst, and L. Young for their advice, and L. Wit, J. Witkowski, T. Weinhold, S. Adams, S. Westerholt, A. Kramer, and M. Maurer (University of Nebraska) for technical assistance. This work was supported in part by the United States Golf Association, the Nebraska Turfgrass Foundation and the Department of Horticulture, University of Nebraska. This is paper number 11560 of the journal series of the Agricultural Research Division, University of Nebraska-Lincoln.

\section{References Cited}

Baxendale, F. P., J. M. Johnson-Cicalese, and T. P. Riordan. 1994. Tridiscus sporoboli and Trionymus sp. (Homoptera: Pseudococcidae): potential new mealybug pests of buffalograss turf. J. Kans. Entomol. Soc. 67: $169-172$.

Beetle, A. A. 1950. Buffalograss-native of the shortgrass plains. Agric. Exp. Stn. Univ. Wyo. Bull. 293: 1-31.

Campbell, W. F., B. A. Haws, K. H. Asay, and J. D. Hansen. 1984. A review of black grass bug resistance in forage grasses. J. Range Manage. 37: 365-369.

Engelke, M. C., and V. G. Lehman. 1990. Registration of 'Prairie' buffalograss. Crop Sci. 30: 1360.

Gaussion, R., F. Baxendale, J. Watkins, and S. Hygnstrom. 1994. Pesticide selection guide for Nebraska professional turfgrass managers. Nebr. Coop. Ext. EC 941558-A.

Heng-Moss, T. 1997. Beneficial arthropods associated with buffalograss and the influence of Rhopus nigroclavatus (Ashmead) on buffalograss mealybug populations. M.S. thesis, University of Nebraska, Lincoln.

Heng, T., J. M. Johnson-Cicalese, F. P. Baxendale, and T. P. Riordan. 1994. A method for monitoring mealybug populations on buffalograss, pp. 55-58. Turfgrass research report for 1993, TRTRR94-1, University of Nebraska, Lincoln.

Huff, D. R., and L. Wu. 1987. Sex expression in buffalograss under different environments. Crop Sci. 27: 623-626.

Johnson-Cicalese, J. M. 1995. Buffalograss resistance to mealybugs: germplasm evaluation, mechanisms and inheritance. Ph.D. dissertation, University of Nebraska, Lincoln.

Johnson-Cicalese, J. M., R. H. Hurley, G. W. Wolfe, and C. R. Funk. 1989. Developing turfgrasses with improved resistance to billbugs, pp. 107-111. In H. Takatoh [ed.], Proceedings of the 6th International Turfgrass Research Conference, Japan Society of Turfgrass Science, c/o Shohucho-Kaikan, Tokyo.

McKenzie, H. L. 1967. Mealybugs of California. University of California Press, Los Angeles, CA.

Meyer, W. A., and C. R. Funk. 1989. Progress and benefits to humanity from breeding cool-season grasses for turf, pp. 31-48. In D. A. Sleper, K. H. Asay and J. F. Pedersen [eds.], Contributions from breeding forage and turf grasses. CSSA Special Publication 15. ASA, CSSA, and SSSA, Madison, WI.

Quisenberry, S. S. 1990 . Plant resistance to insects and mites in forage and turf grasses. Fla. Entomol. 73: 411421.

Reinert, J. A. 1982. A review of host resistance in turfgrasses to insects and acarines with emphasis on the southern chinch bug, pp. 3-12. In H. D. Niemczyk and B. G. Joyner [eds.], Advances in turfgrass entomology. Hammer Graphics, Piqua, OH

Riordan, T. P., S. A. de Shazer, F. P. Baxendale, and M. C. Engelke. 1992. Registration of ' $609^{\prime}$ buffalograss. Crop Sci. 32: 1511 .

Riordan, T. P., S. A. de Shazer, J. M. Johnson-Cicalese, and R. C. Shearman. 1993. An overview of breeding and development of buffalograss. Int. Turfgrass Soc. Res. J. 7: 816-822.

SAS Institute. 1988. SAS/STAT user's guide. SAS Institute, Cary, NC.

Schuster, M. F., and H. A. Dean. 1973. Rhodesgrass scale resistance studies in Rhodesgrass. J. Econ. Entomol, 66: 467-469. 
Skogley, C. R., and C. D. Sawyer, 1992. Field Research, pp. 589-614. In D. V. Waddington, R. N Carrow, and R.C. Shearman [eds.], Turfgrass. No. 32 in the series Agronomy. ASA, CSSA, SSA, Madison, WI.

Smith, C. M., Z. R. Khan, and M. D. Pathak. 1994. Techniques for evaluating insect resistance in crop plants. CRC, Boca Raton, FL.
Southwood, T.R.E. 1979. Ecological methods with particular reference to the study of insect populations, 2nd ed. Wiley, New York.

Wenger, L. E. 1943. Buffalograss. Kans. Agric. Exp. Stn. (Manhattan) Bull. 321: 1-78.

Received for publication 21 June 1996; accepted 24 October 1997 